\title{
The Tarawa Project Part II Resolved Commingling and Identification of Casualties from the Battle of Tarawa
}

\author{
Audrey L. Scott ${ }^{\mathrm{a}} \cdot$ Heli Maijanen $^{\mathrm{b}} \cdot$ Rebecca J. Taylor $^{\mathrm{a}^{*}} \cdot$ Anthony J. Koehl $^{\mathrm{a}, \mathrm{c}} \cdot$ Willa R. Trask ${ }^{\mathrm{a}}$
}

\begin{abstract}
The Battle of Tarawa during World War II resulted in over 7,000 casualties on an approximately three-square-mile Pacific island that necessitated hasty burials, often with poor associated documentation. The loss of original burial information combined with postwar cemetery consolidation efforts resulted in the commingling, disassociation, and loss of identity of casualty remains. This report discusses two cases that are the product of ongoing efforts to recover remains still buried on the Tarawa Atoll and to identify Tarawa unknowns disinterred from the National Memorial Cemetery of the Pacific. Both cases involve the reassociation of disinterred elements to elements recently excavated from their original wartime burial locations on Betio Island. These cases illustrate the steps taken to reassociate elements, the multiple lines of evidence necessary to do so, and the eventual outcome of Tarawa Project identification efforts.

Dental and chest radiograph comparisons of the disinterred remains were used to create and narrow short lists of unaccounted-for service members. These comparisons were combined with historical documentation and DNA analysis of remains recovered from the Tarawa Atoll to suggest association of additional elements. Articulation, refitting of fragments, pair-matching, and osteometric sorting supported the association of the disparate elements to single individuals. Ultimately, the dental and chest radiograph comparisons, biological profile, DNA testing, and historical data led to the positive identification of both individuals. The complicated nature of the Tarawa commingled assemblage emphasizes the importance of a multidisciplinary approach to the resolution and identification of commingled human remains.
\end{abstract}

KEYWORDS: forensic anthropology, commingled remains, Tarawa, World War II

\section{Introduction}

In November 1943 a three-day battle ensued between U.S. and Japanese forces over control of a strategically located airfield on a three-square-mile Pacific island. Over 1,100 U.S. and over 6,000 Japanese forces and Korean conscript laborers were casualties in the 76-hour battle for Betio Island, Tarawa Atoll, Republic of Kiribati (at the time, the Gilbert Islands). The logistics of taking control of the island and utilizing its airfield in combination with the reality of large casualty numbers and a hot, tropical environment led to hasty burials by personnel with limited to no training in proper grave documentation (Alexander 1995; Wukovits 2006). After the battle an additional 23 U.S. service members lost their lives in aircraft crashes or accidents on or around the atoll and were subsequently buried on Betio Island.

\footnotetext{
${ }^{\mathrm{a}}$ Defense POW/MIA Accounting Agency, Joint Base Pearl HarborHickam, Hawai'i, USA

${ }^{\mathrm{b}}$ Oulun Seudun Ammattikorkeakoulu, Archaeology, Oulu, Finland

${ }^{\mathrm{c}}$ SNA International, Alexandria, VA, USA

*Correspondence to: Rebecca J. Taylor, Defense POW/MIA Accounting Agency, 590 Moffet Street, Joint Base Pearl Harbor-Hickam, JBPHH Hawai'i 96853, USA

E-mail: rjwbones@gmail.com
}

Received 5 June 2018; Revised 13 August 2018; Accepted 14 August 2018
Postwar cemetery consolidation efforts led to the repeated disinterment, relocation, and reinterment of U.S. World War II casualties buried overseas, including those buried on Betio Island. Poor initial burial documentation, multiple relocations, and anthropogenic changes to the island resulted in the disjoining, commingling, and loss of identity of many Tarawa casualties (Steere \& Boardman 1957). By the 1949-1951 interment of the Tarawa casualties in their final resting place, the National Memorial Cemetery of the Pacific (NMCP) in Hawai'i, 92 of the approximately 1,100 lost were assigned $\mathrm{X}$-numbers (e.g., $\mathrm{X}$-001) and buried as unknowns. In addition to the 92 unknowns, 219 sets of incomplete remains were interred as a group, while an unknown number of individuals were incompletely or never removed from their original burial locations on Betio Island. To date, over 400 casualties from the Battle of Tarawa remain unaccounted for.

In 2016 the Defense POW/MIA Accounting Agency (DPAA) began disinterment of Battle of Tarawa unknowns from the NMCP in a large-scale project aimed at resolution of commingling and identification of U.S. casualties (for details see Taylor et al. 2019). In addition to the NMCP disinterments, the Tarawa Project includes approximately 6,000 elements from 83 field accessions representing osseous remains recovered from Betio Island. This assemblage also includes remains exposed by storm damage in the 1960s and by infrastructure development in the 1970s. Archaeological 
recoveries of skeletal remains have been ongoing by DPAA, its predecessor organizations, and nongovernmental organizations since the mid-1990s. These recoveries primarily involve partial skeletons in two contexts: assemblages of remains disturbed but redeposited out of respect by those who accidentally discovered them, and elements never recovered from their original burial locations during postwar cemetery consolidation efforts. These latter category contexts usually involved small elements that may be easily missed by those undertaking hurried disinterments with little osteological training: vertebrae, ribs, hands, patellae, and feet (sometimes still in boots). However, intact individual burials have also been recovered.

We will present two cases of skeletal remains disinterred from the NMCP with which elements recovered from ongoing field excavations were associated. The Tarawa Project employs a multidisciplinary approach to facilitate both the association of skeletal and dental elements to a single individual, and as a means to identify missing U.S. service members following standard protocols for analyzing commingled human remains consistent with the prevailing literature (Adams \& Byrd 2014; Jin et al. 2014). All remains in the Tarawa Project undergo a rigorous commingled human remains analysis (for details on methods see Taylor et al. 2019).

\section{Case 1}

In November 2016 a mostly complete skeleton was disinterred from the NMCP as part of the Tarawa Project. The skull was fractured and incomplete; most of the thoracic elements were missing, including the sacrum; the lower left arm was absent; and left foot elements were also absent. The majority of both hands were absent; only two right carpals were recovered. Review of the historical X-number file revealed a dental chart of the remains with two names indicated as possible associations. Both named individuals were killed in the January 1944 crash of a B-24 attempting take off from Betio Island and subsequently buried on the island in the "Main Marine Cemetery" (Cemetery 33).

During analysis, attempts were made to associate the remains with either of the two individuals named in the $\mathrm{X}$-file dental chart. The right maxilla and right portion of the mandible were missing from the remains, thus preventing a full comparison to antemortem dental charts. DNA analysis of remains disinterred from the NMCP has been limited; during postwar identification and consolidation efforts the remains were treated with formaldehyde powder, which inhibits DNA amplification and thus limits traditional sequencing using the Sanger method. All NMCP Tarawa remains must therefore be tested using next-generation sequencing (NGS), which only provides a mitochondrial DNA (mtDNA) profile. Next-generation testing of the right tibia yielded an mtDNA sequence; however, neither candidate had an mtDNA family reference sample (FRS) on file. Additionally, antemortem chest radiographs needed for comparison were not available for either candidate. At that time no other lines of evidence were available and identification efforts were hampered.

In July 2017 the DPAA Laboratory received remains as a unilateral turnover from History Flight, Inc, a nongovernmental organization in partnership with the DPAA. During excavations, skeletal elements had been uncovered in situ with an identification tag bearing the name of one of the two individuals named in the X-number dental chart. An immediate attempt was made to associate the remains recovered from Betio Island and the X-number remains disinterred from the NMCP using the methods normally applied to the commingled assemblages.

The elements recovered from the Betio Island field excavations were first inventoried and found to be the same elements missing from the NMCP assemblage (Fig. 1). The left radius was sampled for DNA analysis but did not yield a profile. The field-recovered left radius, ulna, and foot elements were compared to the NMCP right antimeres and visually pair-matched (Byrd \&Adams 2003). The left radius and ulna exhibited sound anatomical articulation with the disinterred left humerus (Fig. 2). In addition to visual pairmatching and articulation, the left radius and ulna were statistically compared to elements from the right arm using linear regression (Adams \& Byrd 2014; Byrd 2008; Byrd \& LeGarde 2014). The results of the analysis could not provide statistical evidence for excluding either element, thus supporting the association of the left forearm with the assemblage. The left foot similarly articulated with the NMCP left tibia and fibula, and visually pair-matched the NMCP right foot. The majority of the spinal column was recovered during field excavations, including the sacrum, which articulated with the innominates from the NMCP disinterment (Fig. 3). The four vertebrae that were disinterred with the NMCP remains displayed sound anatomical articulations among themselves and with field-recovered vertebrae. The right and left hands were recovered during field excavations, except the right capitate and trapezium, which were included in the NMCP assemblage; all hand elements articulated. Both patellae were recovered and articulated with the NMCP femora, and the sternal body articulated with the disinterred manubrium. Three left ribs and four right ribs were present in the disinterred NMCP assemblage, were morphologically consistent with the nine left and eight right ribs recovered from Betio Island, and articulated with the recovered vertebrae. All possible articulations between the NMCP remains and the elements recovered from field excavations were tested with positive results.

In addition to articulations among elements, several fractured and broken elements had been separated during the 


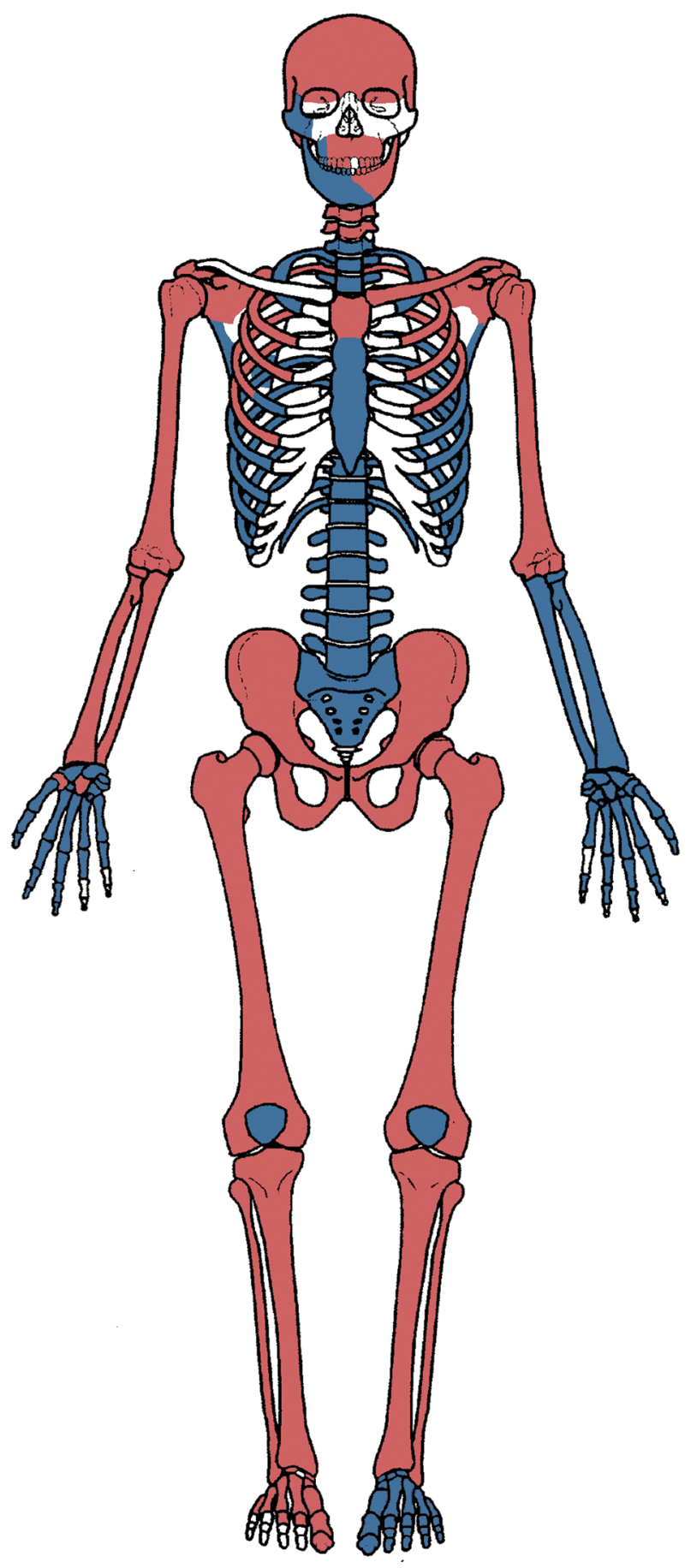

FIG. 1-Homunculus depicting skeletal remains associated with Case 1. Elements depicted in gray were disinterred from the NMCP. Elements depicted in black were recovered from archaeological excavations on Betio Island, Tarawa Atoll, Republic of Kiribati. Elements depicted in white are absent.

postwar cemetery consolidation efforts, yet refit perfectly at the margins. The right scapula, left scapula (Fig. 4), and right fourth rib (Fig. 5) all exhibited postmortem breakage with refitting portions recovered from the two proveniences. The mandible exhibited a midline perimortem fracture consistent

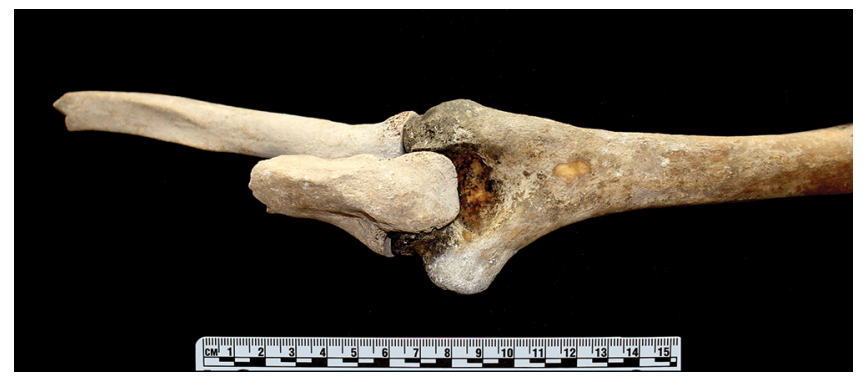

FIG. 2-Case 1, left elbow, posterior view. The humerus (right) was disinterred from the NMCP; the radius and ulna (left) were found in situ with an identification tag in the individual's original burial location. (Photograph by A. Scott)

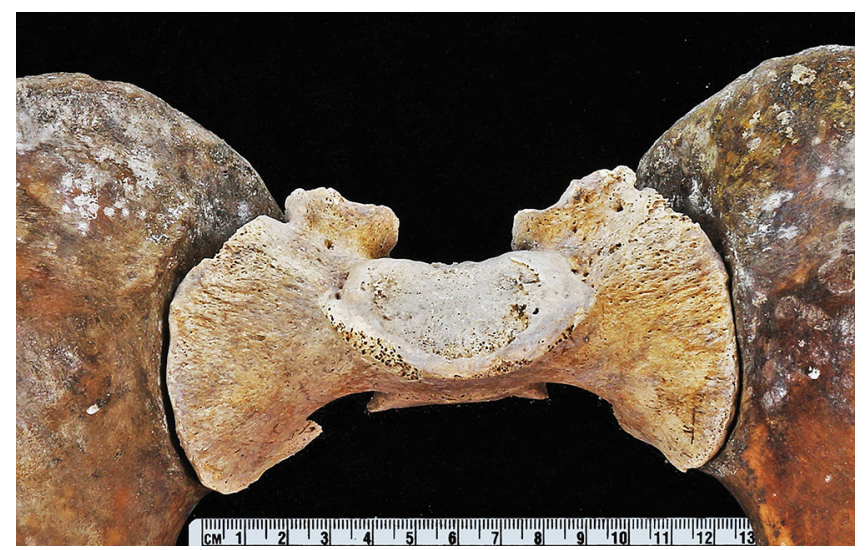

FIG. 3-Case 1, sacro-iliac articulation, superior view. The sacrum was recovered from Betio Island excavations; the os coxae were disinterred from the NMCP. (Photograph by $W$. Lavin)

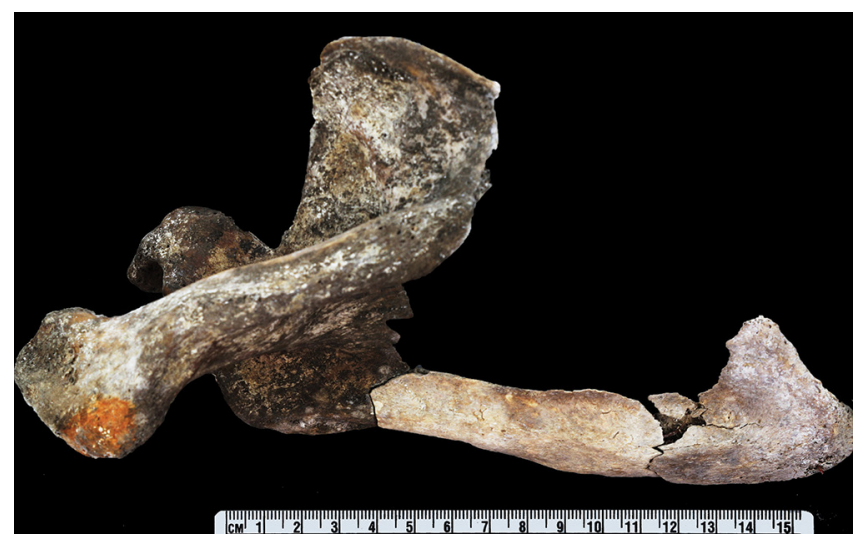

FIG. 4-Case 1, left scapula, posterior view. The lighter portions were excavated from Betio Island; the darker portions were disinterred from the NMCP. (Photograph by W. Lavin)

with the perimortem fragmentation seen in the cranium. The right maxillary alveolus was separated from the body of the maxilla and exhibited a perimortem fracture at the location of the first molar. The right maxillary alveolus anterior to this location was in articulation with the left maxilla. The right 


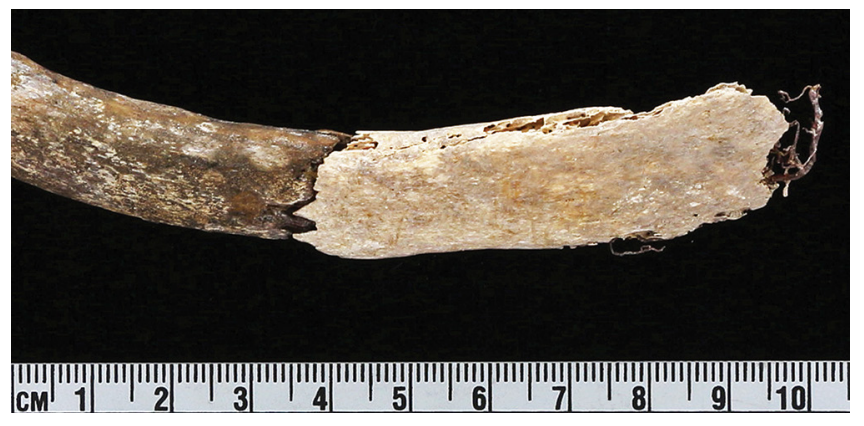

FIG. 5-Case 1, right fourth rib. The lighter sternal end was recovered during field excavations; the darker portion was part of the NMCP disinterment assemblage. (Photograph by W. Lavin)

portions of maxilla and mandible were recovered with the remains excavated on Betio Island and perfectly refit with the left portions disinterred from the NMCP (Fig. 6). The refitting of breakage and fracture margins provided strong support to the association of the field-recovered elements with the NMCP remains.

With the refitting of the maxilla and mandible portions into complete elements, a full dental analysis became possible. Comparison of the dental remains to the antemortem records of the individual named on the identification tag yielded a possible match. At the conclusion of dental analysis, the right mandible portion recovered during field excavation was sampled for DNA analysis. Unlike the remains interred in the NMCP, the remains excavated from their original wartime burial locations regularly yield mtDNA sequences through traditional Sanger method analysis and can be used for nuclear DNA testing. Although no mtDNA

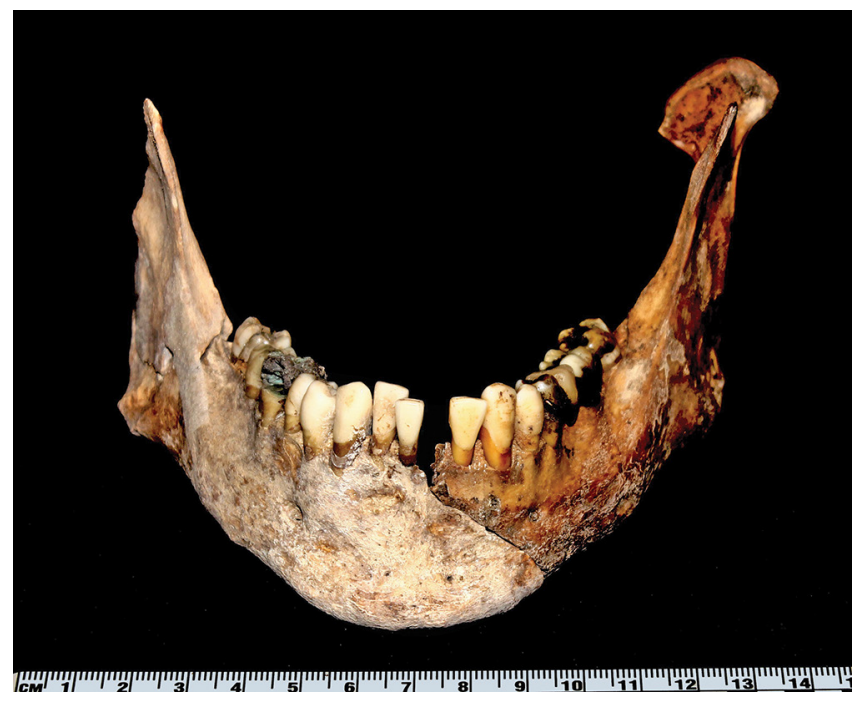

FIG. 6-Case 1, mandible, anterior view. Note two distinct taphonomic signatures on each of the mandible halves (the right portion from Betio Island and the left portion from the NMCP) and the refitting fracture margin. (Photograph by A. Scott)
FRS data were available for the suspected candidate, the Armed Forces DNA Identification Laboratory (AFDIL) had nuclear FRS data on file for comparison. The mandible sample was therefore tested for ySTR and autosomal DNA. According to AFDIL analytic results, the resulting sequences are consistent with the FRS of the service member named on the identification tag.

Although DNA analysis did not contribute to the association of elements in this case, it did contribute to identification. Resolution of the fragmentation was achieved through methods normally utilized in commingled assemblages; pairmatching, articulation, statistical osteometric sorting, and refitting fracture and breakage margins. The re-associated dental remains provided the basis for a possible name association when compared to antemortem dental records. The skeletal elements recovered from the recent field excavations provided the DNA sample necessary for comparison to a FRS and led to the positive identification.

\section{Case 2}

Similar to the first case, Case 2 was disinterred from the NMCP in the autumn of 2016. The cranium was fragmented and incomplete, several vertebrae were missing, all elements of the left arm were absent, and the remains lacked any elements from the hands or feet (Fig. 7). Initial anthropological analysis suggested a minimum of two individuals were represented, as the articulation of the right ulna with the right radius and humerus was questionable. The occipital, right ulna, and right tibia were sampled for NGS analysis and yielded mtDNA to confirm the suspected commingling and aid association of elements.

Comparison of the partial dentition present in the NMCP remains to all Battle of Tarawa casualties produced a probable match to a single candidate. Although several cervical vertebrae were absent from the NMCP remains, a chest radiograph comparison (CXR) to the dental candidate was possible. This comparison found multiple points of concordance between the radiograph of the postmortem clavicles and vertebrae and the antemortem radiograph of the candidate (Fig. 8; Stephan et al. 2011).

The FRS associated with the service member from the CXR and dental association matched with the mtDNA sequence shared by several skeletal elements recovered from Betio Island. In 2013, several large assemblages of fragmented and commingled remains excavated by History Flight, Inc. were unilaterally turned over to the DPAA Laboratory in multiple batches. A left ulna included in one of these assemblages yielded an mtDNA sequence matching the FRS of the single dental and CXR candidate. The ulna was recovered with an articulating left radius. Additionally, four metacarpals, a left patella, a first right metatarsal, and a first left 


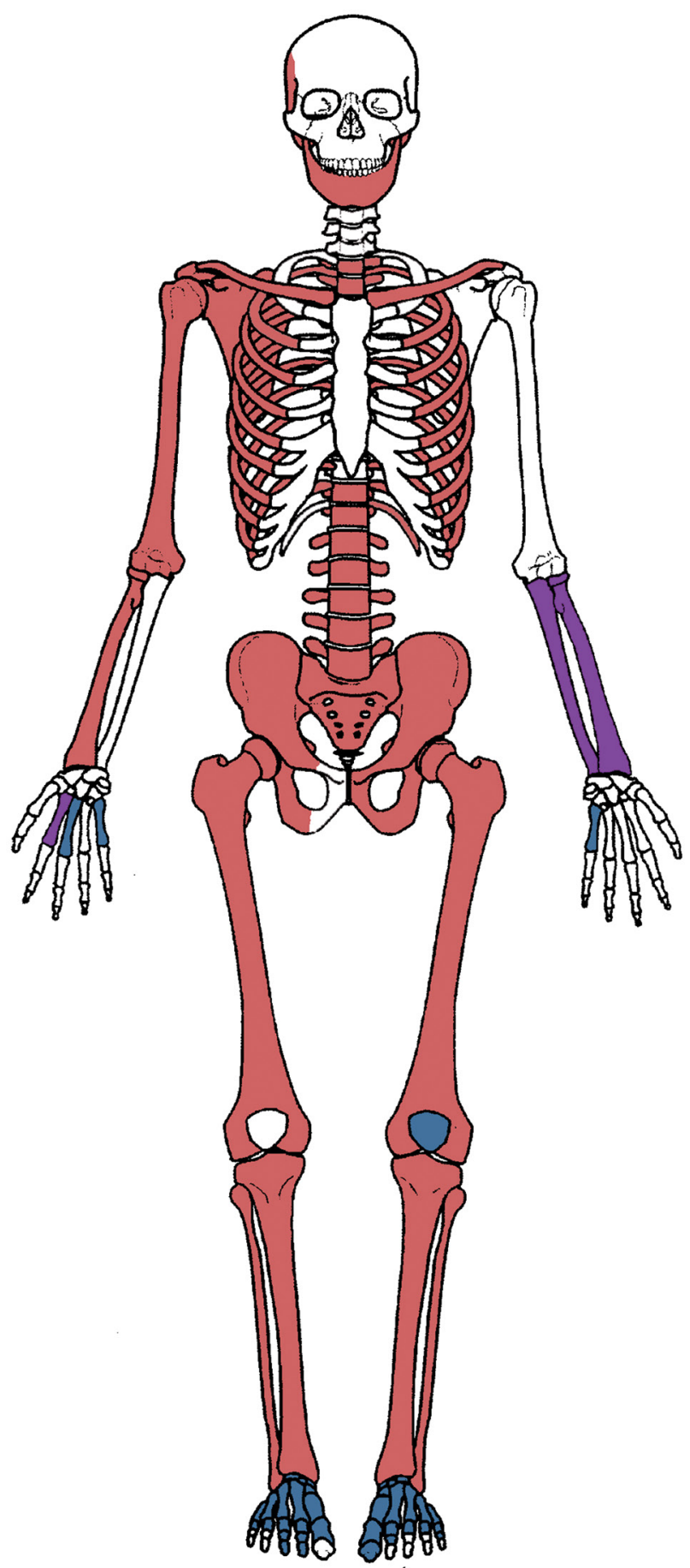

FIG. 7-Homunculus depicting skeletal remains associated with Case 2. Elements depicted in light gray were disinterred from the NMCP. Elements depicted in dark gray and black were recovered during two separate archaeological excavations on Betio Island and subsequently unilaterally turned over to the DPAA Laboratory. Elements depicted in white are absent.

metatarsal all yielded the same mtDNA sequence. These elements originated from two separate field excavations from the same general provenience of a trench burial in the Cemetery 33 area. The NMCP unknown was originally recovered from Cemetery 33 in the 1940s.

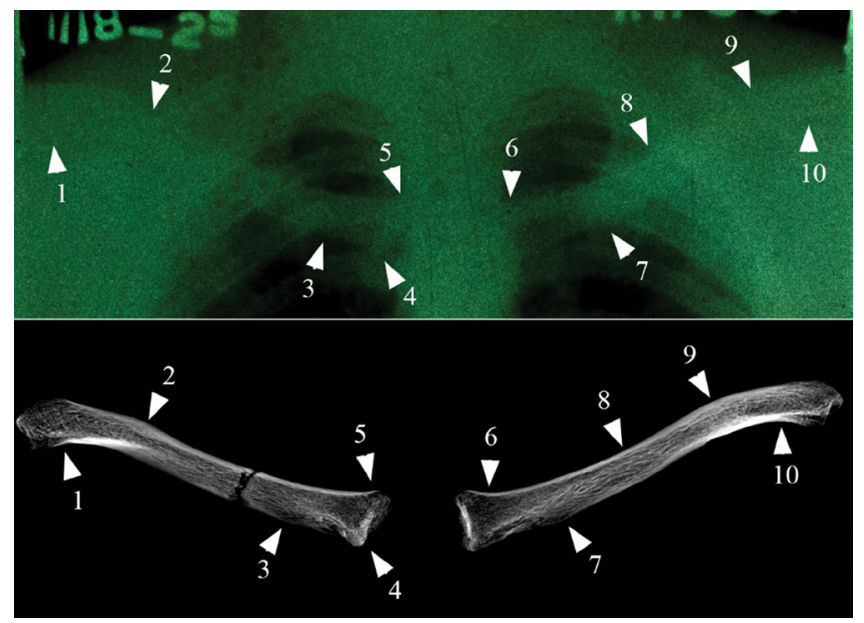

FIG. 8-Case 2, comparison of antemortem chest radiographs of the probable dental match (top) with postmortem radiographs of the left and right clavicles (bottom) white arrows indicate locations of morphological concordance. The images provided are for illustrative purposes only and do not depict the original size and resolution of the images used in the CXR, as these are best viewed onscreen using the electronic file. The difficulty of CXR is illustrated here by the poor quality of the available antemortem radiograph

Anthropological analysis confirmed the association of the mtDNA-sequenced elements recovered from the field in 2013 with the partial skeleton disinterred from the NMCP in 2016. The left radius that was recovered in association with the left ulna visually and statistically pair-matched the NMCP right radius. The right ulna originally disinterred with the remains eventually yielded an mtDNA sequence not matching that of the other elements, confirming the suspicion of commingling within the NMCP casket. The two first metatarsals were recovered in situ within boots in articulation with the entirety of the elements of their respective feet. The tarsals of each foot articulated with the distal tibiae of the NMCP remains. With the reassociation of the field recoveries to the NMCP remains, the DNA analysis required for the disinterred remains was reduced to only the cranial fragments, which could not be articulated with the postcranial elements due to missing portions. The occipital sample yielded an mtDNA sequence matching the sampled field elements.

Despite the original association having been lost through repeated disinterments and reinterments, DNA and anthropological analysis led to the reassociation of elements representing a single individual. The dental evidence, chest radiograph comparison, and mtDNA data taken in totality provided undeniable evidence on which to base an identification of the reassociated remains.

\section{Conclusion}

Since 2016, the Tarawa Project has assisted in the identification of 41 previously unaccounted-for service members, 
including 26 unknowns disinterred from the NMCP. Eight of those cases required the reassociation of skeletal elements recovered from field excavations with remains disinterred from the NMCP. While DNA is often relied upon for association and identification of commingled remains, its use is not always reliable for cases of complex open commingled populations, in which a definite list of missing individuals is not available (Puerto et al. 2014). The ongoing anthropogenic land alterations, lack of original deposition documentation, and occurrence of primary, secondary, and tertiary burials further limit the use of DNA for resolution and identification. Many of the Tarawa cases rely on the ability to associate elements recovered from Betio Island to NMCP disinterred remains through a multifaceted anthropological approach that includes articulation of elements, refitting of fragments, osteometric sorting, and chest radiograph comparisons. DNA analysis and dental comparison provide the basis either for development of preliminary short lists of possible candidates or for identity verification. The two cases discussed here illustrate the complex, multidisciplinary process necessary for resolving commingling and achieving identifications in the Tarawa Project. Due to the nature of the project assemblage, we anticipate more identifications will require the association of elements excavated from their original burial locations to NMCP disinterments. The Tarawa Project, and other ongoing commingled human remains projects, is one facet of the DPAA efforts to achieve the fullest accounting possible of lost U.S. service members.

\section{Acknowledgments}

We would like to acknowledge all of the service members who have made the ultimate sacrifice; DPAA's strategic partner, History Flight, Inc., for their recovery efforts on Betio Island; and our project team and colleagues for feedback on this paper. Special thanks to Ms. Wenona Lavin for element photography.
The opinions presented here are the private views of the authors and do not necessarily reflect those of DPAA, the Department of Defense, or the United States government.

\section{References}

Adams BJ, Byrd JE. Commingled Human Remains: Methods in Recovery, Analysis, and Identification. San Diego: Academic Press; 2014.

Alexander JH. Utmost Savagery: The Three Days of Tarawa. Annapolis, MD: Naval Institute Press; 1995.

Byrd JE. Models and methods for osteometric sorting. In: Adams BJ, Byrd JE, eds. Recovery, Analysis, and Identification of Commingled Human Remains. Totowa, NJ: Humana Press; 2008:199-220.

Byrd JE, Adams BJ. Osteometric sorting of commingled human remains. Journal of Forensic Sciences 2003;48:717-724.

Byrd JE, LeGarde C. Osteometric sorting. In: Adams BJ, Byrd JE, eds. Commingled Human Remains: Methods in Recovery, Analysis, and Identification. San Diego: Academic Press; 2014:167-192.

Jin J, Burch AL, LeGarde C, Okrutny E. The Korea 208: A largescale commingling case of American remains from the Korean War. In: Adams BJ, Byrd JE, eds. Commingled Human Remains: Methods in Recovery, Analysis, and Identification. San Diego: Academic Press; 2014:407-424.

Puerto MS, Egana S, Doretti M, Vullo CM. A multidisciplinary approach to commingled remains analysis: Anthropology, genetics, and background information. In: Adams BJ, Byrd JE, eds. Commingled Human Remains: Methods in Recovery, Analysis, and Identification. San Diego: Academic Press; 2014: 307-335.

Steere E, Boardman TM. Final Disposition of World War II Dead, 1945-51. Quartermaster Corps, QMC Historical Studies, Series II, No. 4, Washington DC: U.S. Army; 1957.

Stephan CN, Winburn AP, Christensen AF, Tyrrell AJ. Skeletal identification by radiographic comparison: Blind tests of a morphoscopic method using antemortem chest radiographs. Journal of Forensic Sciences 2011;56:320-322.

Taylor RJ, Scott AL, Koehl AJ, Trask WR, Maijanen H. The Tarawa Project Part I: A multidisciplinary approach to resolve commingled human remains from the Battle of Tarawa. Forensic Anthropology 2019;2(2):87-95.

Wukovits J. One Square Mile of Hell: The Battle for Tarawa. New York: New American Library; 2006. 